\title{
PRESCRIBING TREND AND DRUG COST ANALYSIS OF ORAL HYPOGLYCEMIC AGENTS USING DRUG UTILISATION REVIEW
}

\author{
Nivethita Chanthran ${ }^{1}$, Long Chiau Ming ${ }^{2}$, Ching Siang Tan ${ }^{1 *}$, Shashidharan Menon ${ }^{1 *}$, H. Jaasminerjiit \\ Kaur ${ }^{1}$, Anandarajagopal Kalusalingam ${ }^{1}$, Abdullah Khan ${ }^{1}$, Mei Jun Loy ${ }^{3}$ and Mohamed Mansor Manan ${ }^{4}$ \\ ${ }^{1}$ School of Pharmacy, KPJ Healthcare University College, Negeri Sembilan, Malaysia \\ 2PAPRSB Institute of Health Sciences, Universiti Brunei Darussalam, Gadong, Brunei Darussalam \\ ${ }^{3}$ Faculty of Engineering, Universiti Teknologi Malaysia, Johor, Malaysia \\ ${ }^{4}$ Faculty of Pharmacy, Universiti Teknologi MARA, Puncak Alam Campus, Selangor, Malaysia
}

Corresponding author: Shashidharan Menon, Ching Siang Tan

Email:_ucn.shashidharan@kpjuc.edu.my; tcsiang@kpjuc.edu.my

\section{ABSTRACT}

Drug utilization of oral hypoglycemic agents (OHAs) in a private healthcare setting is useful to examine the prescribing pattern of OHAs, especially the newer fixed dose combination (FDC) products. This study was aimed to evaluate the prescribing pattern of OHAs indicated for Type 2 diabetes mellitus (T2DM), to determine the costs of OHAs prescribed and total cost per prescription in the treatment of T2DM in an outpatient department of a private hospital located in central Malaysia. Retrospective review of electronic medical record (EMR) study design was adopted. Patient's demographic characteristics, medications prescribed, prescribers' details and cost per prescription were documented. Defined daily dose (DDD) of OHAs and drug cost were calculated. Research ethics protocol was approved and no personal data was collected. Out of the 396 EMR screened, 135 fulfilled the inclusion criteria and subsequently were analysed. In term of demography, mean age of the sample was 51 years old with 59\% were male and ethnicity composition of $71 \%$ Malay and 19\% Chinese. Metformin and "metformin+dipeptidyl peptidase-4 inhibitor" (DPP-4i) were the most commonly prescribed single-drug and $\mathrm{FDCOHA}$, respectively. Average cost of $\mathrm{OHAs}$ and total cost per prescription was less than USD 68 and USD 185, respectively. Meanwhile, FDC covered $28.91 \%$ of incidences of prescriptions, but $44.6 \%$ of cost and SGTL-2i covered $9 \%$ incidences of prescriptions and 16.29\% of cost. Prescribing pattern of OHA was appropriate based on patient's T2DM diagnosis, however, dosage given were not in accordance with WHO DDD.

Keywords: Drug Utilization Review, Diabetes Mellitus, Oral Hypoglycemic Agents, Prescribing pattern, Defined Daily Dose

\section{INTRODUCTION}

A study conducted by Fauziah ${ }^{[27]}$ under Malaysian Pharmaceutical Services Division on Malaysian Statistics on Medicines 2009 \& 2010 revealed of metformin usage as highest among all oral hypoglycaemic agents (OHA), while total drug consumption of sulphonylureas (SU) has increased (16.2\%) from $2007 / 2008$ to $2009 / 2010$ particularly gliclazide. The numbers comply with Clinical Practice Guidelines Management of T2DM (5th Edition) because data were collected from the government hospitals usage but lacking information from private sector in Malaysia in the treatment of T2DM.

Drug utilization review in private hospital able to justify whether over or underutilization of oral hypoglycaemic agents is crucial for rational prescribing of drugs by prescribers. The aim is to assess the utilisation of OHAs in T2DM patients in outpatient department of a private hospital by understanding prescribing pattern, analysing and comparing defined daily dose (DDD) with WHO DDD standard and costs of OHAs prescribed as well as total cost per prescription. The prediction factor could help private healthcare providers to develop new drug policy and improve management of T2DM.

\section{METHODS}

The study conducted by retrospective observational design to understand drug utilization in outpatient department of KPJ Damansara Specialist Hospital for two weeks. The inclusion criteria include newly registered and existing patients prescribed OHAs as monotherapy or fixed dose combination therapy but as single active pharmaceutical agent. Only outpatient Type II DM included followed by any patient aged between 18 to 64 years old, and either sex. Exclusion criteria were incomplete data collection form, walk-in outpatient prescription and patients diagnosed with gestational diabetes under $\mathrm{OHA}$ by Bahri ${ }^{[9]}$.

OHAs was identified from hospital drug formulary, and label based on Anatomical Therapeutic Chemical (ATC) Classification System. During the 
study period all outpatient patients was screened based on the inclusion and exclusion criteria using poison book and KPJ Clinical Information System (KCIS). Enrolled patient data was collected using data collection form consist Part A includes patient's demographic information (age, gender, race, MRN), Part $B$, information on prescribed OHAs (pharmacological classification, dosage form, dose, frequency) and in Part C, type of prescribers and their speciality. HITS system was used to obtain data on unit price of each OHAs and total cost of medication per prescription were retrieved.

Demographic information and prescribing record of each patient were analysed descriptively and statistically by using the Statistical Package for Social Science (SPSS) program version 22.0 which were expressed in mean and standard deviation. The DDD was computed based formula derived from Manitoba Centre for Health Policy. The ethical issues and informed consent have been approved KPJUC/RMC/BPH//EC/2017/99.by Research Ethics Committee by of KPJ University
College, Nilai, Malaysia. This approval has been obtained before conducting.

\section{RESULTS}

The demographic characteristics of the patients' selected were shown in Table 1.

Table 2 shows list of OHAs with WHO DDD and total consumption of each individual drug based on its strength as calculated for each user per day and per 1000 residents. The highest utilised drug was FDC metformin/sitagliptin for two strengths $50 / 850 \mathrm{mg}$ and $50 / 1000 \mathrm{mg}$, metformin/ dapagliflozin $10 / 1000 \mathrm{mg}$ and metformin/ vildagliptin 50/1000 mg. Metformin/sitagliptin $50 / 850 \mathrm{mg}$ accounted 3.51 DDDs / user /day, while metformin/sitagliptin $50 / 1000 \mathrm{mg}$ was 3.93 DDDs / user /day. Highest consumption of individual drug was, empagliflozin $25 \mathrm{mg}$ with 2.86 DDDs and dapagliflozin $10 \mathrm{mg} 2.2$ DDDs for every user for every day of the month. In contrast, metformin XR $500 \mathrm{mg}$ and empagliflozin $10 \mathrm{mg}$ had a lower DDD if compared to WHO DDD. DDD for some of the OHAs adheres to the international guideline such as pioglitazone $30 \mathrm{mg}$ and linagliptin $5 \mathrm{mg}$.

Table 1: Demographic Characteristic and Cost of medication supplied

\begin{tabular}{|c|c|c|c|}
\hline \multirow{2}{*}{$\begin{array}{l}\text { Characteristic } \\
\text { Gender }\end{array}$} & \multicolumn{3}{|c|}{ Frequency (Percentage \%) } \\
\hline & & & \\
\hline Male & \multicolumn{3}{|c|}{$80(59.3)$} \\
\hline Female & \multicolumn{3}{|c|}{$55(40.7)$} \\
\hline \multicolumn{4}{|l|}{ Age } \\
\hline$<34$ years & \multirow{3}{*}{\multicolumn{3}{|c|}{$\begin{array}{c}4(3.0) \\
79(58.5) \\
52(38.5)\end{array}$}} \\
\hline 35 to 54 years & & & \\
\hline$>54$ years & & & \\
\hline \multicolumn{4}{|l|}{ Ethnicity } \\
\hline Malays & \multicolumn{3}{|c|}{$96(71.1)$} \\
\hline Chinese & \multicolumn{3}{|c|}{$25(18.5)$} \\
\hline Indian & \multicolumn{3}{|c|}{$6(4.4)$} \\
\hline Others & \multicolumn{3}{|c|}{$8(6.0)$} \\
\hline \multicolumn{4}{|l|}{ Types of therapy } \\
\hline Monotherapy & \multicolumn{3}{|c|}{$48(35.6)$} \\
\hline Polytherapy & \multicolumn{3}{|c|}{$21(15.6)$} \\
\hline Monotherapy + FDC & \multicolumn{3}{|c|}{$26(19.4)$} \\
\hline Polytherapy + FDC & \multicolumn{3}{|c|}{$40(29.4)$} \\
\hline Characteristic & Frequency* & & Cost (RM) \\
\hline \multicolumn{4}{|l|}{ Pharmacological Classification } \\
\hline Biguanides & 47 & & 5051.00 \\
\hline Alpha Glucosidase Inhibitor & 1 & & 174.00 \\
\hline Sulphonylurea & 38 & & 8248.00 \\
\hline DPP4-Inhibitor & 2 & & 538.00 \\
\hline Thiazolidines & 1 & & 336.00 \\
\hline SGLT2-Inhibitor & 11 & & 5978.00 \\
\hline
\end{tabular}

Note : Frequency* $N=$ more then 135 because multiple drug and combination drug 
Table 2 : Shows list of OHAs with WHO DDD and total consumption of each individual drug based on its strength as calculated for each user per day and per 1000 residents.

\begin{tabular}{|c|c|c|c|c|c|c|c|c|c|}
\hline Drug Name & $\begin{array}{l}\text { WHO } \\
\text { DDD } \\
\text { (mg) }\end{array}$ & $\begin{array}{l}\text { DDD/ } \\
\text { strength } \\
\text { (DDD) }\end{array}$ & $\begin{array}{c}\text { Total } \\
\text { number } \\
\text { of tablets }\end{array}$ & $\begin{array}{c}\text { DDD rates } \\
\text { (DDDs/ } \\
\text { month) }\end{array}$ & $\begin{array}{c}\text { Rates/ } \\
\text { residents/ } \\
\text { day }\end{array}$ & $\begin{array}{c}\text { Total } \\
\text { number of } \\
\text { users }\end{array}$ & $\begin{array}{c}\text { Rates/user/ } \\
\text { day }\end{array}$ & $\begin{array}{c}\text { Total } \\
\text { duration } \\
\text { (days) }\end{array}$ & $\begin{array}{l}\text { Intermediate } \\
\text { rates }\end{array}$ \\
\hline Metformin $500 \mathrm{mg}$ & 2000 & 4 & 1863 & 466 & 0.31 & 10 & 1.55 & 816 & 82 \\
\hline Metformin XR 500 mg & 2000 & 4 & 3300 & 825 & 0.55 & 33 & 0.83 & 2580 & 78 \\
\hline Metformin $850 \mathrm{mg}$ & 2000 & 2.35 & 2544 & 1081 & 0.72 & 25 & 1.44 & 1294 & 52 \\
\hline Metformin XR 850 mg & 2000 & 2.35 & 120 & 51 & 0.034 & 1 & 1.7 & 60 & 60 \\
\hline Acarbose $100 \mathrm{mg}$ & 300 & 3 & 390 & 130 & 0.09 & 2 & 2.17 & 150 & 75 \\
\hline Gliclazide 60 mg & 60 & 1 & 1798 & 1798 & 1.20 & 56 & 1.07 & 3084 & 55 \\
\hline Sitagliptin 100 mg & 100 & 1 & 90 & 90 & 0.06 & 2 & 1.5 & 90 & 30 \\
\hline Linagliptin 5 mg & 5 & 1 & 30 & 30 & 0.02 & 1 & 1 & 30 & 30 \\
\hline Pioglitazone 30 mg & 30 & 1 & 30 & 30 & 0.02 & 1 & 1 & 30 & 30 \\
\hline Dapagliflozin 10 mg & 10 & 1 & 731 & 731 & 0.49 & 11 & 2.2 & 701 & 64 \\
\hline Empagliflozin $10 \mathrm{mg}$ & 17.5 & 1.75 & 65 & 37 & 0.02 & 2 & 0.62 & 65 & 33 \\
\hline Empagliflozin 25 mg & 17.5 & 0.7 & 360 & 514 & 0.34 & 6 & 2.86 & 360 & 60 \\
\hline Metformin/ vildagliptin $50 / 1000 \mathrm{mg}$ & $1 \mathrm{DDD}$ & $1 \mathrm{DDD}$ & 360 & 360 & 0.24 & 3 & 4 & 210 & 70 \\
\hline Metformin/sitagliptin 50/500 mg & $1 \mathrm{DDD}$ & $1 \mathrm{DDD}$ & 240 & 240 & 0.16 & 2 & 4 & 120 & 60 \\
\hline Metformin/sitagliptin XR 50/500 mg & $1 \mathrm{DDD}$ & $1 \mathrm{DDD}$ & 360 & 360 & 0.24 & 3 & 4 & 210 & 70 \\
\hline Metformin/sitagliptin 50/850 mg & $1 \mathrm{DDD}$ & $1 \mathrm{DDD}$ & 2210 & 2210 & 1.47 & 21 & 3.51 & 1141 & 54 \\
\hline Metformin/sitagliptin 50/1000 mg & $1 \mathrm{DDD}$ & $1 \mathrm{DDD}$ & 1650 & 1650 & 1.1 & 14 & 3.93 & 870 & 62 \\
\hline Metformin/sitagliptin XR 50/1000 mg & 1 DDD & $1 \mathrm{DDD}$ & 455 & 455 & 0.3 & 6 & 2.53 & 244 & 41 \\
\hline Metformin/saxagliptin $2.5 / 1000 \mathrm{mg}$ & $1 \mathrm{DDD}$ & $1 \mathrm{DDD}$ & 270 & 270 & 0.18 & 3 & 3 & 180 & 60 \\
\hline Metformin/ dapagliflozin 5/1000 mg & $1 \mathrm{DDD}$ & $1 \mathrm{DDD}$ & 570 & 570 & 0.38 & 5 & 3.8 & 510 & 102 \\
\hline Metformin/ dapagliflozin 10/1000 mg & $1 \mathrm{DDD}$ & $1 \mathrm{DDD}$ & 240 & 240 & 0.16 & 2 & 4 & 240 & 120 \\
\hline Metformin/linagliptin $2.5 / 850 \mathrm{mg}$ & 1 DDD & $1 \mathrm{DDD}$ & 60 & 60 & 0.04 & 1 & 2 & 30 & 30 \\
\hline Metformin/glyburide $2.5 / 500 \mathrm{mg}$ & $1 \mathrm{DDD}$ & $1 \mathrm{DDD}$ & 60 & 60 & 0.04 & 1 & 2 & 30 & 30 \\
\hline
\end{tabular}


Metformin/sitagliptin 50/850 mg and 50/1000 mg were found to be dispensed of 1.47 DDDs and 1.1 DDDs of biguanides/ 1000 residents/ day. Pioglitazone $30 \mathrm{mg}$ and linagliptin $5 \mathrm{mg}$ resulted in 0.02 persons out of every 1000 person. Metformin XR $500 \mathrm{mg}$ and Metformin $850 \mathrm{mg}$ showed higher number of people treated among the biguanides. Metformin XR $500 \mathrm{mg}$ and Metformin $850 \mathrm{mg}$ resulted in 0.55 and $0.72 \mathrm{DDDs} /$ 1000 residents /day. This shows that $0.055 \%$ of patients were treated with Metformin XR $500 \mathrm{mg}$ and $0.072 \%$ of patients were treated with Metformin $850 \mathrm{mg}$. Proportion of people treated daily with Gliclazide $60 \mathrm{mg}$ was 1.2 DDDs. Overall, the drug consumption varies than those recommended by WHO DDD.

Metformin/sitagliptin 50/850 mg and 50/1000 mg were found to be dispensed of 1.47 DDDs and 1.1 DDDs of biguanides/ 1000 residents/ day. Pioglitazone $30 \mathrm{mg}$ and linagliptin $5 \mathrm{mg}$ resulted in 0.02 persons out of every 1000 person. Metformin XR $500 \mathrm{mg}$ and Metformin $850 \mathrm{mg}$ showed higher number of people treated among the biguanides. Metformin XR $500 \mathrm{mg}$ and Metformin $850 \mathrm{mg}$ resulted in 0.55 and $0.72 \mathrm{DDDs} /$ 1000 residents /day. This shows that $0.055 \%$ of patients were treated with Metformin XR $500 \mathrm{mg}$ and $0.072 \%$ of patients were treated with Metformin $850 \mathrm{mg}$. Proportion of people treated daily with Gliclazide $60 \mathrm{mg}$ was 1.2 DDDs. Overall, the drug consumption varies than those recommended by WHO DDD.

\section{DISCUSSION}

\section{Demographic Characteristics}

In Japan, there are larger numbers of T2DM patients in male than female by Ishii [26]. National Survey of Health and Nutrition 2015 in Japan indicated that the number of T2DM patients are $15.5 \%$ in men and $9.8 \%$ in women its contras in Malaysia where NHMS 2015 results, reported male was $16.7 \%$ while female is $18.3 \%$ where T2DM was higher in females. This study findings show more males than females, where Kautzky-Willer ${ }^{[19]}$ highlighted that, men develop impaired fasting glucose (IFG) more often than female which is due to increase in hepatic glucose output leading to impairment of early insulin secretion. We need more data and longer duration of study and more sample to very whether it is due to population settlement or pathophysiologic changes between male and female

A positive relationship is observed between older age and prevalence of diabetes in this study. Another similar study in Malaysia has mentioned that diabetes was lowest between the age group of 30-39 and increase with aging by Rampal [24]. However, age group between 35-54 proved to be significantly higher in individuals compared to those above 54 because findings showed, younger patients were more prone to seek their treatment anywhere based on the convenience of their location, ability to pay the service charged by hospital and time constraints, while older patients were more inclined to go to government clinics for their treatment as per findings by Feisul MI, Azmi $S$ [12]. Malay ethnicity preponderance is observed in this study. Malays has highest body mass index (BMI) as mentioned by Ahmed ${ }^{[6]}$ and obesity rate in comparison to another Asian groups Hong ${ }^{[13]}$.

\section{Drug Utilization based on Pharmacological Classification}

Total number of drugs that has been prescribed by its generic names were $100 \%$ which is equal to the WHO standardized value $(100 \%)$ by Isah ${ }^{[15]}$. The reason is this private hospital is using electronic prescribing system at which generic names were entered into the system making it easier for prescribers to choose rationally the most appropriate drug for the patients. Generic prescribing helps prescriber to choose a brand drug that has good bioequivalence as innovator drug. There is also increase in accessibility, affordability and availability with flexibility in stocking as according to Okoro [21]. Generic prescribing also helped to reduce pharmaceutical cost as mentioned by Karim ${ }^{[18]}$ and burden of the patients. This also help patients to remember names of their medications more easily leading to reduction of medication error by Weant ${ }^{[29]}$. The significance of electronic prescribing system is, prescribers are able to choose among the alternatives that are available without limited among the brand drugs only.

Overall, monotherapy predominated over multiple-therapy. Results from a study done by Syed ${ }^{[28]}$ is in line with these findings where monotherapy is used as a first line treatment, followed by second line with combinations of 2 or more OHAs. If glycemic control is not achieved by monotherapy, only then a combination therapy will be initiated based on CPG of T2 DM by Kamarudin ${ }^{[16]}$. Commonly prescribed monotherapy is biguanide (metformin) which is about $47 \%$, as metformin is the cheapest drug if compared to other OHAs in this private hospital, thus patients who are economically low can afford it. Metformin is weight neutral and suitable for obese patients, safe drug as it rarely causes hypoglycaemia. According to Alex [7], metformin helps to reduce excess hepatic gluconeogenesis without increasing the insulin level. This prescribing pattern is in line with other studies by Ramachandran ${ }^{[23]}$. According to Kamarudin ${ }^{[16]}$ in CPG of T2 DM and in Guideline of American Diabetes Association (ADA) have recommended metformin as the first line agent of T2DM.

\section{Defined Daily Dose of OHAs/ Combination drugs}

When the recommended blood glucose level could not be achieved with monotherapy, combination therapy is used among diabetic patients. 
According to International Diabetes Federation (IDF) Guideline [14], a combination with metformin+DPP-4i or metformin+SGLT2-i is used as an initial combination therapy in management of diabetes. The rate of prescribed FDC usage was the highest based on the DDD calculated such as metformin/sitagliptin. Metformin/sitagliptin can help to improve adherence and do not cause severe hypoglycaemia as caused by SU group. Empagliflozin and dapagliflozin from the therapeutic classification of SGLT2-i was used highly as it is one of the new drugs in the pharmaceutical market released in 2014 with moderate efficacy, low risk of hypoglycaemia and weight loss. Gliclazide was one of the most used drugs from the SU group, and this pattern is in line with another study by Bakar ${ }^{[10]}$, as it is proven to reduce risk of macrovascular outcomes. But, this differs with other studies which mentioned glimepiride as the most utilised drug in the SU therapeutic classification as stated by $\mathrm{Alti}^{[8]}$, and metformin in biguanide group Kannan ${ }^{[17]}$.

Calculated DDD varied compared to WHO DDD showing an underutilization or overutilization for some of the drugs which might be due to sample size used in this study which did not represent the whole population. Acarbose was used low and the probable reason is acarbose is less effective in reducing glucose level of patient by Kamarudin ${ }^{[16]}$. Metformin overutilization was because it is the most commonly used drugs and it is recommended as the first line treatment based on CPG of T2DM. A study by Saqib ${ }^{25]}$ also suggested that, differentiation in the mean observed doses to WHO DDD were due to the variation in prescribing pattern and it may be country specific. This shows dose for each patient differs from WHO DDD as dosing prescribed in the private hospital is based on individual characteristics (age, ethnicity, comorbidities) and also pharmacokinetic considerations. Small sample size of this study also caused results could not be generalised.

\section{Cost of OHAs/ Combination drugs}

Based on a study by Abougalambou [2], Malaysia, cost of antidiabetic drugs covers about $59.2 \%$ of the total treatment cost. This shows that the prevalence and cost of this disease are increasing. Mean \pm SD total cost of prescription in this findings has been reported to be RM 756.86ะ933.70 and this could be because patients are having other comorbidities which increases total cost that was accounted for per prescription. Piette ${ }^{[22]}$ has supported that it is common for people with diabetes to have other comorbid conditions. Also, patients with multiple therapy may have higher degree of severity and complications. As most of the study populations' prescription come from different clinics (cardiology, endocrinology), thus the complexity of medication regimen prescribed is also greater as supported by Dybicz et al. ${ }^{[11]}$ and this is more prevalent among the older adults Abdelhafiz \& Sinclair ${ }^{[1]}$. This is proven when $74 \%$ of the prescriptions containing five and more drugs have at least one cardiovascular drug such as Angiotensin Converting Enzyme inhibitors or statins.

FDC medications (which mainly included metformin with DPP-4i agents) and SGTL-2i have a higher cost even though made up of only $28.91 \%$ and $9 \%$ of the prescriptions, respectively. On the other hand, metformin as a single formulation yielded a lower cost even though it made up of $33 \%$ of the total prescription items. The increase expenditure of FDC may be to improve patients' compliance and provide synergistic effect. However, according to a study by Ahmad ${ }^{[5]}$, some countries have started price regulation schemes to control medication affordability for patients such as, National Pharmaceutical Pricing Authority in Britain and social insurance schemes in Germany and Japan. However, there is no any price policies implemented in Malaysia, allowing private hospitals to mark up their price of medicines and this increases the burden of patients. Thus, a price controlled strategy in private hospitals has to be developed to allow patients to use it as a reference before purchasing their medications.

\section{Limitations \& Future Study}

Limitation faced in the study was geriatric patient no information on laboratory data $(\mathrm{HbA} 1 \mathrm{C}$, and blood glucose level) and other comorbidities which influences could prescription pattern. Short duration of study due to time constrain, need full population study to have concrete prediction value. With this, feedback to prescribers on prescribing practices can be given for a more costeffective treatment option and improve patients' quality of care. More parameters such as clinical values, morbidity and mortality related data to be analysed as individual OHAs for longer duration of time to other include chronic disease as well in a private hospital

\section{CONCLUSION}

In conclusion the study able to satisfy all the objective where utilisation pattern of $\mathrm{OHA}$ was appropriate when compare to WHO DDD guidelines but dosage given were not in accordance to WHO DDD. Male predominated in this study with Metformin being the most prescribed OHA. Cost of OHAs and total cost per prescription was high where fixed dose combination covers $28.91 \%$ total drug use but contribute $44.6 \%$ of cost and while in single drug use SGTL-2i covered 9\% from total use and $16.29 \%$ of cost. Further intervention on reducing cost of drugs for patient has to be taken by reducing average number of drugs prescribed based on patients' needs and preferences. Choice of 
medication should be individualised based on patients' age, comorbidities and complications, affordability, advantages and disadvantages of each drug.

\section{REFERENCES}

1. Abdelhafiz, Ahmed H., \& Sinclair, Alan J. (2013). Management of Type 2 Diabetes in Older People. Diabetes Therapy, 4(1), 13-26. doi: $10.1007 / \mathrm{s} 13300-013-0020-4$

2. Abougalambou SSI, Abougalambou AS \& Ahmed NO. (2019) Anti-Diabetic Medication Cost of Type 2 Diabetic Patients at Tertiary Center in Malaysia. Int J Diabetes Curr Res, 1(1): $1-9$

3. Abu BA, Abdul GA. NonCommunicable Diseases, Risk Factors \& Other Health Problems. Institute for Public Health, Ministry of Health Malaysia; (2015). 292p. Report No.: 2.

4. Abu Bakar NS AHJ, Syed Ahmad Yunus SZ, Eliana Musa NS, Abu Sapian R, Abdul Halim NH, Zainuddin NA. Descriptive Analysis of Type 2 Diabetes Mellitus Patients Using Data From Hospital Information System. Malaysian Journal of Medicine and Health Sciences. 2020;16(1).

5. Ahmad NS, Islahudin F. Affordability of essential medicine prices in Malaysia's private health sector. Patient prefer adherence 2018;12:12311237https://doi.org/10.2147/PPA.S1 51603.

6. Ahmed KA, Muniandy S, Ismail IS, Ali $\mathrm{RS}$, Alhamodi ZH. Evaluation of $\mathrm{N} \hat{\mathrm{I}} \mu$ (carboxymethyl) lysine and lipid peroxidation in multiethnic Malaysian subjects with type 2 diabetes mellitus. Scientific Research and Essays. 2011;6(9):1957-62.

7. Alex, S. M., Sreelekshmi, B., Smitha, S., Jiji, K., Menon, A. S., \& Uma Devi, P. (2015). Drug utilization pattern of anti-diabetic drugs among diabetic outpatients in a tertiary care hospital (Vol. 8).

8. Alti A, Latha SP, Nagarjun GL, Nagaraju G, Gopinath C, Madhav PM. A Study on Drug Utilization Pattern and Effectiveness of Oral Hypoglycemic Agents in Diabetes
Mellitus. PharmaTutor. 2015 Jul 1;3(7):31-7.

9. Bahri S, Abdul Aziz AM. Drug Utilization in the Treatment of Diabetes Mellitus in the Ministry of Health Facilities. Pharmaceutical Service Division; (2013). 115p.

10. Bakar S, Ab hamid J, Syed Ahmad Yunus SZ, Abdul Halim N, Zainuddin N. Descriptive Analysis of Type 2 Diabetes Mellitus Patients Using Data From Hospital Information System. 2020;16:94.

11. Dybicz, S. B., Thompson, S., Molotsky, S., \& Stuart, B. (2011). Prevalence of diabetes and the burden of comorbid conditions among elderly nursing home residents. $\mathrm{Am} \mathrm{J}$ Geriatr Pharmacother, 9(4), 212-223. doi:10.1016/j.amjopharm.2011.05.0 01

12. Feisul, I. M., Azmi, S., Mohd Rizal, A. M., Zanariah, H., Nik Mahir, N. J., Fatanah, I., Goh, A. (2017). What are the direct medical costs of managing Type 2 Diabetes Mellitus in Malaysia? Med J Malaysia, 72(5), 271-277.

13. Hong CY, Chia KS, Hughes K, Ling SL. Ethnic differences among Chinese, Malay and Indian patients with type 2 diabetes mellitus in Singapore. Singapore medical journal. 2004 Apr;45(4):154-60.

14. International Diabetes Federation. Recommendations For Managing Type 2 Diabetes In Primary Care, 2017. www.idf.org/managing-type2diabetes.

15. Isah AO, Ross-Degnan D, Quick J, Laing R, Mabadeje AF. The development of standard values for the WHO drug use prescribing indicators. International conference on improving use of medicines (ICIUM). INRUD-Nigeria1, Support Group 2008 (Vol. 2).

16. Kamarudin NA, Omar AM, Clinical Practice Guideline of Management of Type II Diabetes Mellitus. Ministry of Health; (2015).

17. Kannan S, Arshad, Senthil K. A study on drug utilization of oral hypoglycemic agents in type-2 
diabetic patients. Asian J Pharm Clin Res. 2011; 4:560-4.

18. Karim SA, Pillai G, Ziqubu-Page TT, Cassimjee MH, Morar MS. Potential savings from generic prescribing and generic substitution in South Africa. Health policy and planning. 1996 Jun 1;11(2):198-202.

19. Kautzky-Willer, Alexandra, Harreiter, Jürgen, \& Pacini, Giovanni. (2016). Sex and Gender Differences in Risk, Pathophysiology and Complications of Type 2 Diabetes Mellitus. Endocrine Reviews, 37(3), 278-316. doi: 10.1210/er.2015-1137.

20. Kuritzky L, Samraj GP. Enhanced glycemic control with combination therapy for type 2 diabetes in primary care. Diabetes Therapy. 2011 Sep $1 ; 2(3): 162$.

21. Okoro RN, Nmeka C, Erah PO. Utilization study of antidiabetes medicines at a tertiary care hospital in Nigeria. Future Journal of Pharmaceutical Sciences. 2018;4(2):109-15.

22. Piette JD, Kerr EA. The impact of comorbid chronic conditions on diabetes care. Diabetes care. 2006 Mar 1;29(3):725-31.

23. Ramachandran G, Rohith V, Topno I. Evaluation of prescribing pattern of anti-diabetic drugs using WHO prescribing indicators in a tertiary care hospital in Puducherry: A crosssectional study. The Pharma Innovation. 2015 Jul 1;4(5, Part B):76.

24. Rampal S, Rampal L, Rahmat R, Zain AM, Yap YG, Mohamed M, Taha M. Variation in the prevalence, awareness, and control of diabetes in a multiethnic population: a nationwide population study in Malaysia. Asia Pacific Journal of Public Health. 2010 Apr;22(2):194202.

25. Saqib A, Atif $M$, Scahill S. Drug utilization evaluation among an elderly population: a retrospective cross-sectional study in a tertiary care hospital in Pakistan. Journal of Pharmaceutical Health Services Research. 2018 Jun;9(2):123-32.

26. Shimizu $F$, Ishii $Y$, Ogawa $M$, Takao $T$, Matsuoka K. Age and Gender Influence Differently on Various Foods Intakes, Body Mass Index (BMI), and Levels of Various Plasma Parameters in Young and Old Men and Women in Japan. Obes Open Access. 2017;3(3).

27. Siti Fauziah A, Kamarudin A, Nik Nor Aklima NO. Malaysian Statistics on Medicines 2009 \& 2010. Malaysia: Pharmaceutical Services Division and Clinical Research Centre, Ministry of Health. 2014 Dec.

28. Syed Ahmad Yunus SZ, Abu Bakar NSb, Musa NSEb, Abu Sapian R, Azahar A, Zainuddin NAb. Anti-diabetic drugs utilization pattern and its cost in managing Type 2 Diabetes patients in hospitals in Selangor, Malaysia. Informatics in Medicine Unlocked. 2018;13:21-5.

29. Weant KA, Bailey AM, Baker SN. Strategies for reducing medication errors in the emergency department. Open access emergency medicine: OAEM. 2014; 6:45 